Editorial

\title{
$32{ }^{\text {nd }}$ Conference of the European Colloid and Interface Society, 2-7 September 2018 in Ljubljana,
} Slovenia

This special issue of Colloids and Surfaces A showcases original contributions from the participants of the $32^{\text {nd }}$ Conference of the European Colloid and Interface Society (ECIS2018). The articles cover a wide range of topics, such as emulsions, surfaces polyelectrolytes, nanoporous materials, nanoparticles and microgels, which reflects the multidisciplinary profile of annual ECIS meetings.

The ECIS2018 conference was held in in Ljubljana at the Union Congress Centre. The organizers of the conference were Prof. Dr Marija Bešter-Rogač (Chair), Dr Ana Kroflič (co-Chair) and Prof. Dr Venčeslav Kaučič (co-Chair). The conference was organized jointly by the University of Ljubljana (Faculty of Chemistry and Chemical Technology, Faculty of Pharmacy, Biotechnical Faculty, Faculty of Mathematics and Physics), the National Institute of Chemistry, the Jožef Stefan Institute and the Slovene Chemical Society.

The aim of the ECIS2018 conference was to bring together chemists, physicists, biologists and engineers on a single platform to converge their expertise and ideas in the interdisciplinary field of colloid and interface science, to exchange ideas and discoveries, promote contacts, exchange visits between laboratories, prepare projects, promote networks, and propel any other issue that arises from the creative minds of the participating colloidal scientists. The topics covered fundamental and applied advances in interfaces, dispersed systems, wetting, complex fluids, micro- and nano-materials, nanoparticles, specific-ion effects, self-assembly of surfactants, polymers and proteins, and advances in theory and instrumentation.

Besides the sessions devoted to the 12 topics of the ECIS2018 conference, there was also an additional satellite session with the title "Modern Engineering of Colloids and Interfaces", hosting a group of invited speakers. Sadly, the international colloid and interface community lost six prominent representatives of outstanding professional authority last year: Hans Lyklema, Dotchi Exerowa, Dimo Platikanov, Kåre Larsson, Helmuth Möhwald and Ivan B. Ivanov. They were honoured with a memorial session.

Following the tradition of ECIS, a pre-conference Training Course was also held before the ECIS2018 conference. This year, the 2-day course called "Using thermodynamics in characterization: From colloids and self-assembled systems to biological macromolecules" took place at the Faculty of Chemistry and Chemical Technology, University of Ljubljana and was attended by 20 students from 15 countries.

Altogether, 629 participants from 47 countries of all continents attended the conference in 2018. The scientific programme consisted of 6 plenary lectures. Amongst these, one was given by a Solvay prize winner and one an Overbeek medal winner. Furthermore, we had 37 keynote lectures, 13 invited and 24 selected by the International scientific committee, who also selected 177 oral presentations from more than 400 submitted abstracts for oral presentations. Across three poster sessions, 375 posters were presented.

The Overbeek Gold Medal 2018 that recognizes careers of scientific excellence and inspiring contributions to the field of colloid and interface science was awarded to Henk N. W. Lekkerkerker (Utrecht, the Netherlands). He gave a plenary lecture on "Self-organised structures in suspensions of mineral colloidal plates: From colloidal liquid crystals to self-assembled nanocomposites".

The ECIS-Solvay Prize 2017, which is granted to a European scientist for original scientific work of outstanding quality, was awarded to Horst Weller (Hamburg, Germany), who gave a plenary lecture entitled "Quantum dots and other nanocrystals: from basic science to applications in materials and life sciences".

The Enzo Ferroni Prize acknowledging the top-level scientific activity of young researchers in the field of colloid and interface science was awarded to Michele Zanini (ETH, Switzerland).

The Langmuir Award to the best oral presentations of young scientists was given to three young scientists: Maria Chiara di Gregorio (Weizmann Institute of Science, Rehovot, Israel), Anne-Laure Famea (INRA, Nantes, France) and Remi Merindol (Centre de Recherche Paul Pascal, Université de Bordeaux, Pessac, France).

At the ECIS2018 conference, two prizes for young scientists were introduced for the first time: the Substantia Award for the top level scientific activity in the field of colloid and interface science (Axel Rüter, Lund University, Sweden) and the Exerowa-Platikanov Award for best oral contribution in the thematic trend of surface forces, foams and emulsions (Maja Vuckovac, Aalto University School of Electrical Engineering, Espoo, Finland)

The Poster Prizes sponsored by Elsevier were awarded to Dennis Noll (Friedrich-Alexander-Universität Erlangen-Nürnberg, Germany), Jan Kumar (University of Ljubljana, Slovenia), Jordan Bye (University of Manchester, United Kingdom), Kanako Watanabe (Tohoku University, Sendai, Japan), Naval Singh (Loughborough University, United Kingdom), and Tanja Goršak (Jožef Stefan Institute, Ljubljana, Slovenia)

The $33^{\text {rd }}$ ECIS conference will take place in Leuven, Belgium, 8-13 September 2019. You are cordially invited to contribute to its scientific excellence!

Marija Bešter-Rogač

University of Ljubljana, Faculty of Chemistry and Chemical Technology, Večna pot 13, 1000 Ljubljana, Slovenia

Ana Kroflič National Institute of Chemistry, Department of Analytical Chemistry, Hajdrihova 19, 1000 Ljubljana, Slovenia 
Carlos Rodríguez-Abreu Institute of Advanced Chemistry of Catalonia (IQAC), Spanish National Research Council (CSIC) and Biomedical Research Networking Center in
Bioengineering, Biomaterials and Nanomedicine (CIBER-BBN), Jordi Girona 18-26, 08034 Barcelona, Spain 